\title{
Proteomics-based identification of TMED9 is linked to vascular invasion and poor prognoses in patients with hepatocellular carcinoma
}

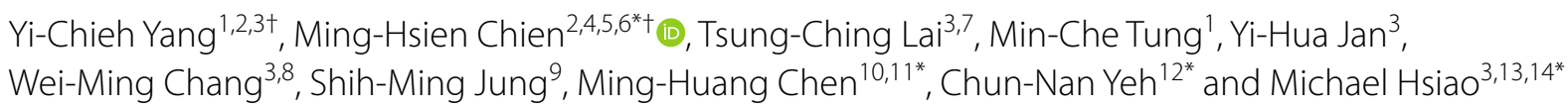

\begin{abstract}
Background: Due to the difficulties in early diagnosing and treating hepatocellular carcinoma (HCC), prognoses for patients remained poor in the past decade. In this study, we established a screening model to discover novel prognostic biomarkers in HCC patients.

Methods: Candidate biomarkers were screened by liquid chromatography with tandem mass spectrometry (LC-MS/ MS) analyses of five HCC normal (N)/tumor ( $\mathrm{T}$ ) paired tissues and preliminarily verified them through several in silico database analyses. Expression levels and functional roles of candidate biomarkers were respectively evaluated by immunohistochemical staining in $\mathrm{N} / \mathrm{T}$ paired tissue $(n=120)$ and MTS, colony formation, and transwell migration/ invasion assays in HCC cell lines. Associations of clinicopathological features and prognoses with candidate biomarkers in HCC patients were analyzed from GEO and TCGA datasets and our recruited cohort.

Results: We found that the transmembrane P24 trafficking protein 9 (TMED9) protein was elevated in HCC tissues according to a global proteomic analysis. Higher messenger (m)RNA and protein levels of TMED9 were observed in HCC tissues compared to normal liver tissues or pre-neoplastic lesions. The TMED9 mRNA expression level was significantly associated with an advanced stage and a poor prognosis of overall survival (OS, $p=0.00084)$ in HCC patients. Moreover, the TMED9 protein expression level was positively correlated with vascular invasion $(p=0.026)$, OS $(p=0.044)$, and disease-free survival $(p=0.015)$ in our recruited Taiwanese cohort. In vitro, manipulation of TMED9 expression in HCC cells significantly affected cell migratory, invasive, proliferative, and colony-forming abilities.
\end{abstract}

\footnotetext{
${ }^{*}$ Correspondence: mhchien1976@gmail.com; mhchen9@gmail.com; ycn@cgmh.org.tw; mhsiao@gate.sinica.edu.tw

${ }^{\dagger}$ Yi-Chieh Yang and Ming-Hsien Chien contributed equally to this work.

${ }^{2}$ Graduate Institute of Clinical Medicine, College of Medicine, Taipei

Medical University, Taipei 11031, Taiwan

${ }^{3}$ Genomics Research Center, Academia Sinica, 128 Academia Road,

Section 2, Nankang, Taipei 11529, Taiwan

${ }^{10}$ Department of Oncology, Taipei Veterans General Hospital and School

of Medicine, National Yang-Ming University, Taipei 112, Taiwan

${ }^{12}$ Department of General Surgery and Liver Research Center, Linkou

Branch, Chang Gung Memorial Hospital, Chang Gung University,

Taoyuan 333, Taiwan

Full list of author information is available at the end of the article
}

(c) The Author(s) 2021. Open Access This article is licensed under a Creative Commons Attribution 4.0 International License, which permits use, sharing, adaptation, distribution and reproduction in any medium or format, as long as you give appropriate credit to the original author(s) and the source, provide a link to the Creative Commons licence, and indicate if changes were made. The images or other third party material in this article are included in the article's Creative Commons licence, unless indicated otherwise in a credit line to the material. If material is not included in the article's Creative Commons licence and your intended use is not permitted by statutory regulation or exceeds the permitted use, you will need to obtain permission directly from the copyright holder. To view a copy of this licence, visit http://creativecommons.org/licenses/by/4.0/. The Creative Commons Public Domain Dedication waiver (http://creativeco mmons.org/publicdomain/zero/1.0/) applies to the data made available in this article, unless otherwise stated in a credit line to the data. 
Conclusions: Ours is the first work to identify an oncogenic role of TMED9 in HCC cells and may provide insights into the application of TMED9 as a novel predictor of clinical outcomes and a potential therapeutic target in patients with HCC.

Keywords: Hepatocellular carcinoma, Mass spectrometric imaging, Transmembrane P24 trafficking protein 9, Vascular invasion, Prognosis

\section{Background}

Hepatocellular carcinoma ( $\mathrm{HCC})$ is the most fatal malignancy disease among primary liver cancers and is one of the leading causes of cancer-related deaths worldwide [1]. HCC develops from underlying chronic liver disease and cirrhosis, which are usually caused by hepatitis B and $\mathrm{C}$ viral (HBV and $\mathrm{HCV}$ ) infections, alcohol consumption, or diabetes and nonalcoholic fatty liver disease [2-4]. The incidence of HCC is highest in Asia, including Taiwan, and Africa, and it occurs in males more often than in females [5]. The median survival time of HCC in Taiwan is significantly higher than that in Africa, where the median survival is only 2.5 months [6]. To the present, several therapeutic strategies have been applied as HCC treatment, including chemoradiotherapy, surgery, and systemic therapy with sorafenib $[7,8]$, but low therapeutic and diagnostic efficiencies still lead to severe mortality of patients with this disease. Thus, we wanted to illuminate novel biomarkers for HCC diagnoses or therapeutic targets.

Images from computed tomography $(\mathrm{CT})$ or magnetic resonance imaging (MRI) are key approaches for evaluating the progression of $\mathrm{HCC}$ and formulating future treatment plans [9]. In addition, a high serum alphafetoprotein (AFP) level has also been widely used for HCC diagnoses and recurrence predictions. However, due to its low sensitivity and specificity, serum AFP is not a highly accurate biomarker for HCC diagnoses [10]. Recently, systemic proteomic analyses have shown promise in exploring proper biomarkers for predicting cancer prognoses [11]. For example, matrix-assisted laser desorption/ionization (MALDI)-imaging mass spectrometry (IMS), multiple reaction monitoring (MRM) MS and liquid chromatography-tandem MS (LC-MS/MS) have been used to discover diagnostic, prognostic and survival biomarkers in liver cancer [12-15]. Although MS protein expression data in HCC are available from recently published works, the prognostic values and functional roles of these proteins in clinical HCC samples and HCC cells have not yet been investigated $[12,14,16]$.

Herein, we mined candidate biomarkers of $\mathrm{HCC}$ from five paired normal and HCC tissues using LC-MS/MS analyses. Among the candidate proteins, overexpression of transmembrane P24 trafficking protein 9 (TMED9) was observed in HCC samples and pre-neoplastic lesions compared to normal tissues. HCC patients with TMED $9^{\text {high }}$ tumors had a higher frequency of developing an advanced stage and vascular invasion, and had shorter overall survival (OS) and disease-free survival (DFS) times compared to patients with TMED9 $9^{\text {low }}$ tumors. Moreover, TMED9-knockdown significantly inhibited the growth and motility of HCC cell lines. Taken together, this study first identified that TMED9 might be a novel prognostic biomarker and therapeutic target for HCC.

\section{Material and methods Cell culture}

The human Mahlavu and HCC36 cell lines were respectively maintained in the Dulbecco's modified Eagle and minimum essential medium (DMEM and MEM; Gibco, Waltham, MA, USA) with $10 \%$ fetal bovine serum (FBS), $2 \mathrm{mM}$ glutamine, 100 units $/ \mathrm{mL}$ penicillin, and $100 \mathrm{mg} /$ $\mathrm{mL}$ streptomycin, and was incubated in a $5 \% \mathrm{CO}_{2}$ humidified atmosphere at $37^{\circ} \mathrm{C}$. The TMED9 short hairpin (sh) RNA constructs were purchased from the National RNAi core Facility at Academic Sinica (Taipei, Taiwan). The target sequences were GCC AGT CTT CTG TCT TCC TTT and CGG CAC CTC AAG AGC TTC TTT. The HA-TMED9 construct was purchased form Applied Biological Materials Inc.

\section{In-gel digestion}

Coomassie dye staining gels were cut into small pieces and washed with distilled water $\left(\mathrm{d}_{2} \mathrm{H}_{2} \mathrm{O}\right)$. Gel pieces were destained with $25 \mathrm{mM}$ ammonium bicarbonate (ABC) overnight at $4{ }^{\circ} \mathrm{C}$, which was then replaced with reduction buffer (10 mM dithiothreitol (DTT)/25 mM ABC) for $1 \mathrm{~h}$ at $56^{\circ} \mathrm{C}$. Next, the reduction buffer was discarded, and alkylation buffer (55 mM iodoacetamide/25 mM $\mathrm{ABC}$ ) was added for $1 \mathrm{~h}$ at room temperature in the dark and washed twice with $40 \%$ acetonitrile $(\mathrm{ACN})$ for $10 \mathrm{~min}$ and then dehydrated by treatment with $100 \%$ ACN. Dry pieces were re-swollen with $0.12 \mu \mathrm{g}$ of modified trypsin in $25 \mathrm{mM} \mathrm{ABC}$ and digested overnight at $37^{\circ} \mathrm{C}$. Peptides were harvested using $60 \% \mathrm{ACN} / 0.1 \%$ trifluoroacetic acid (TFA) and sonication. After the solution was dried in a vacuum, the peptides were re-dissolved in $0.1 \%$ TFA for the LC-MS/MS analysis. 


\section{LC-MS/MS analysis}

LC-MS/MS analyses were performed on an LTQ-FT ion trap mass spectrometer (LTQ FT Ultra, Thermo Scientific, Waltham, MA, USA). The Mascot software package (Matrix Science, Boston, MA, USA) was used for protein identification according to SWISS-PROT, an annotated protein sequence database [17]. The peptide mass tolerance and fragment mass tolerance were set at $100 \mathrm{ppm}$ and $0.25 \mathrm{Da}$, respectively. Matches with scores higher than the $95 \%$ confidence level were regarded as significant.

\section{Cell-proliferation and colony-formation assays}

Mahlavu and HCC36 cells were stably infected with virus carrying either shTMED9, HA-TMED9, or their respective controls. For the proliferation assay, Mahlavu $\left(5 \times 10^{3}\right)$ and HCC36 $\left(6 \times 10^{3}\right)$ cells were seeded into 96-well dishes. After 48 (for HCC36) or $72 \mathrm{~h}$ (for Mahlavu), Alamar blue dye was added to each well and incubated at $37{ }^{\circ} \mathrm{C}$ for $3 \mathrm{~h}$. The absorbance was measured at $570 \mathrm{~nm}$ using a microplate reader (MQX200; Bio-Tek Instruments, Winooski, VT, USA). Values are the mean \pm standard deviation (SD) of triplicate wells and were normalized to that of the control group to determine the multiples of proliferative ability.

For the colony-formation assay, $1.5 \times 10^{3}$ Mahlavu cells were seeded into 6-well dishes. After 7-10 days, cells were fixed with methanol and then stained with $1 \%$ crystal violet. Numbers of colonies were further quantified by Image J software (National Institutes of Health, Bethesda, MD, USA).

\section{Transwell migration and Matrigel-invasion assays}

For the cell-migration analysis, $10^{5}$ HCC36 cells infected with virus carrying the Luc-control or HATMED9 were plated in an uncoated top chamber (24well insert; pore size, $8 \mu \mathrm{m}$; Corning Costar, Corning, $\mathrm{NY}$ ). For the cell-invasion analysis, $1.5 \times 10^{4}$ Mahlavu cells infected with virus carrying the sh-control or shTMED9 were seeded in a $20 \mu \mathrm{g}$ Matrigel (BD Biosciences, Bedford, MA)-coated top chamber. In both assays, top chamber all contained serum-free medium and medium supplemented with serum was used as a chemoattractant in the lower chamber. After 48 and $24 \mathrm{~h}$ of incubation, migrated and invaded cells in the lower chamber were fixed with methanol and stained with $0.1 \%$ crystal violet. The number of cells migrating through or invading through the membrane was counted under a light microscope $(\times 100$, five random fields per well).

\section{Bioinformatics analysis}

We collected the GSE6764, GSE76311, and GSE102079 microarray datasets, which contain transcriptome profiles of normal tissues, dysplastic tissues, and HCC tissues, from the Gene Expression Omnibus (GEO) database [18-20]. Representative figures for the RNA sequencing analysis were obtained from the visualization platform Gene Expression Profiling Interactive Analysis (GEPIA) (http://gepia.cancer-pku.cn/) [21]. Further, the website STRING (https://string-db.org/) was utilized to explore protein-protein interaction networks of TMED9-regulated genes, and the cBioPortal (https://www.cbioportal.org/) was used to investigate correlations of TMED9 with other genes. Correlations of TMED3 with TMED9 and with patient prognosis data were calculated and downloaded from UCSC Xena (https://xena.ucsc.edu/) [22].

\section{Patients and tissue microarray (TMA) construction}

This study is a hospital-based case-control study. A total of 182 patients who had undergone surgical resection of HCC at Taipei Veterans General Hospital in Taipei, Taiwan were recruited as a case group between 1990 and 2006, with an average follow-up time of 60.02 months. The patients were diagnosed with HCC according to the characteristic criteria of the national guidelines for HCC. Collection of patient data was approved by the Ethics Committee of Taipei Veterans General Hospital (201010021IC). We constructed a formalin-fixed, paraffin-embedded TMA composed of $182 \mathrm{HCC}$ tissue cores. The clinicopathologic data of 182 patients with HCC were obtained by a retrospective review of the medical records. Before 2002, patients with tumor recurrence could receive transarterial chemoembolization, surgery, and a percutaneous ethanol injection. After 2002, other therapeutic choices, such as radiofrequency tumor ablation and liver transplantation, were provided for recurrent patients. Because approval of targeted therapy or immunotherapy was not available in 1990 to 2006, no patients in this study received that drug. Collection of our Taiwanese HCC cohort was described in detail in our previous study [23].

\section{Immunohistochemical (IHC) staining}

IHC staining was automatically performed with an immunostainer (Ventana Discovery XT autostainer, Tucson, AZ, USA). TMA slides were stained with a polyclonal rabbit anti-human TMED9 antibody (GeneTex, Hsinchu, Taiwan), and cytoplasmic expression in HCC cells was evaluated. The staining intensity and percentage of TMED9 were recorded for further analysis. According to the intensity of staining, samples were scored from 0 (no staining) to 3 (heavy staining). The percentage of positive cells was calculated to range $0-100 \%$. The intensity score was multiplied by the percentage of positive cells as 
the final IHC score (0-300). The high or low expression of TMED9 in HCC patients was divided by a cutoff value of 60 .

\section{Western blotting}

Protein extraction and Western blot preparation were described in a previous study [24]. The primary antibodies used in this study were TMED9 (1:1000; GeneTex, Hsinchu, Taiwan); TGF- $\alpha$ (1:250; Santa Cruz, CA, USA), p-ERK (1:1000; Santa Cruz, CA, USA), GLI1 (1:1000; Santa Cruz, CA, USA), $\beta$-catenin (1:1000; Cell Signaling, MA, USA), p-STAT3 (1:1000; Cell Signaling, MA, USA), t-STAT3 (1:1000; Cell Signaling, MA, USA), t-ERK (1:1000; Cell Signaling, MA, USA), and GAPDH (1:5000, Sigma, St. Louis, MO, USA).

\section{Dot blot analysis}

Briefly, $5 \times 10^{5} \mathrm{HCC}$ cells were seeded in a 6-cm Petridish and infected with virus carrying either shTMED9, HA-TMED9, or their respective controls. After infection, the cell culture medium was replaced by serum-free medium for another $24 \mathrm{~h}$ and harvested for dot blotting. Each dot was presented the proteins in $300 \mu \mathrm{L}$ soup. The hybridization and detection were followed by Western blot protocol.

\section{Statistical analysis}

All spectra were processed by baseline subtraction, peak detection, and peak-area calculation according to default settings. Discrimination between control and tumor samples was performed using an algorithm. Values from in vitro studies are presented as the mean \pm standard deviation (SD). Data were analyzed using Student's $t$-test when two groups were compared. Correlations of TMED9 with clinicopathologic features of HCC were examined by Pearson's Chi-squared test. Cumulative survival was analyzed by the Kaplan-Meier method. Risk factors affecting survival were assessed by a Cox proportional hazards regression model. A $p$ value of $<0.05$ was considered a statistically significant difference.

\section{Results}

Potential biomarkers of HCC are discovered by the LC-MS/ MS analysis

In this study, we first applied sodium dodecyl sulfate polyacrylamide gel electrophoresis (SDS-PAGE) coupled with LC-MS/MS to identify candidate biomarkers from five sets of paired HCC N/T tissues. Fresh protein lysates from paired N/T tissues were separated by SDSPAGE and analyzed by LC/MS/MS. Then, protein IDs were identified by a Mascot engine through searching the SWISS-PROT database, and protein expression levels were calculated according to Mascot scores. Hematoxylin and eosin (H\&E) staining of samples was used by a pathologist to define the cancer and non-cancerous parts (Fig. 1a). By interpretation of the protein ID analysis and a literature search, we selected several candidate proteins which had $a>1$ and those with $\mathrm{a}<1$ score ratio of HCC tumor versus normal samples (Table 1, Additional file 1: Table S1).

We next validated the prognostic values of these 20 HCC tissue-upregulated candidates by online databases, including SurvExpress (http://bioinformatica.mty.itesm.
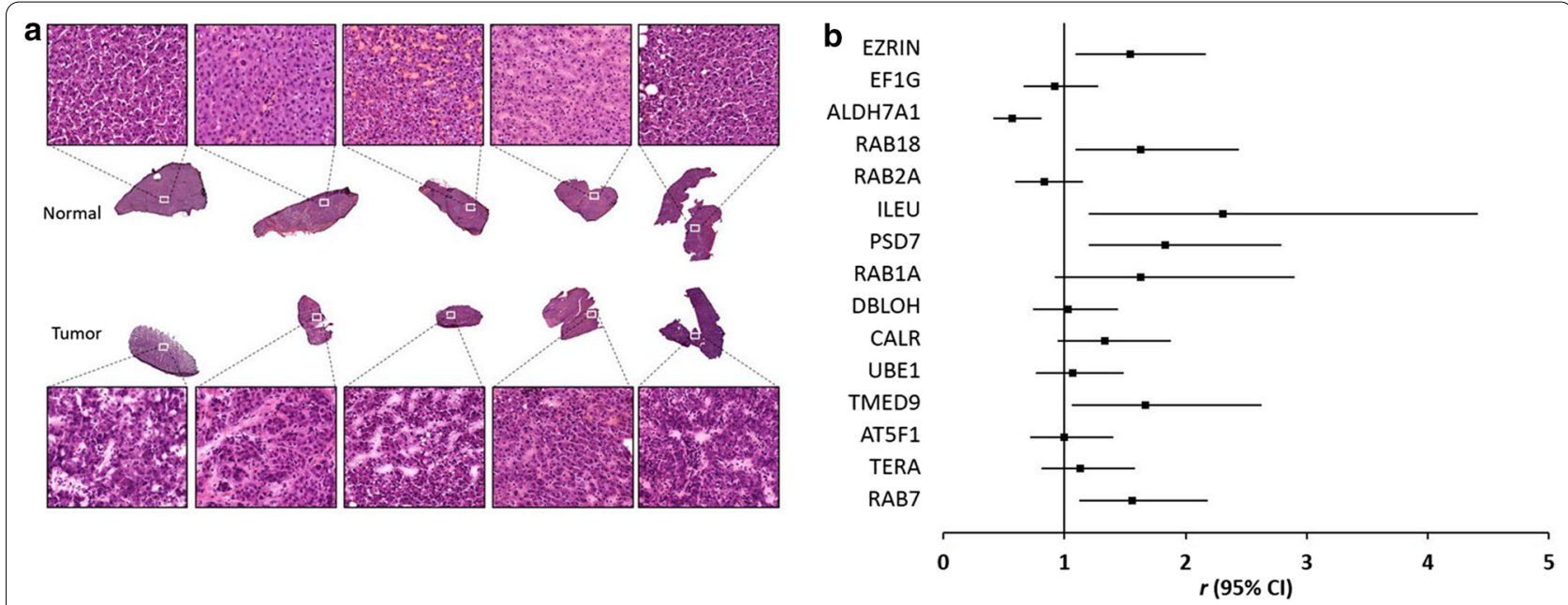

Fig. 1 Clinical values of candidate genes derived from an LC-MS/MS analysis of paired normal (N)/tumorous (T) hepatocellular carcinoma (HCC) samples. a Representative H\&E staining pictures of the histomorphology of normal and HCC samples. b Forest plot showing hazard ratios (HRs) and $95 \%$ confidence intervals for the association of candidate genes and overall survival in patients with HCC 
Table 1 List of protein score ratios (>1) of hepatocellular carcinoma (HCC) tumor (T) versus normal (N) samples

\begin{tabular}{|c|c|c|c|}
\hline Protein ID & Mass & $\mathrm{T} / \mathrm{N}$ & SE \\
\hline Ezrin & 69,370 & 4.73 & 0.99 \\
\hline Elongation factor 1-gamma & 50,087 & 4.01 & 0.81 \\
\hline Aldehyde dehydrogenase family 7 member A1 & 55,331 & 3.51 & 0.90 \\
\hline Calcium-binding mitochondrial carrier protein Aralar2 & 74,129 & 2.84 & 0.48 \\
\hline Ras-related protein Rab-18 & 22,963 & 2.68 & 0.39 \\
\hline Ras-related protein Rab-2A & 23,531 & 2.41 & 0.23 \\
\hline Leukocyte elastase inhibitor (LEI) (Serpin B1) & 42,715 & 2.24 & 0.30 \\
\hline 265 proteasome non-ATPase regulatory subunit 7 & 37,002 & 2.23 & 0.15 \\
\hline Ras-related protein Rab-1A & 22,663 & 1.83 & 0.26 \\
\hline Proteasome subunit beta type 5 precursor & 22,882 & 1.81 & 0.19 \\
\hline Diablo homolog, mitochondrial precursor & 27,114 & 1.75 & 0.11 \\
\hline 4-trimethylaminobutyraldehyde dehydrogenase & 53,767 & 1.69 & 0.15 \\
\hline Calreticulin precursor & 48,112 & 1.59 & 0.11 \\
\hline Ubiquitin-activating enzyme E1 & 117,774 & 1.55 & 0.27 \\
\hline Transmembrane emp24 domain-containing protein 9 precursor & 25,089 & 1.47 & 0.12 \\
\hline Cytochrome c & 11,741 & 1.45 & 0.15 \\
\hline ATP synthase subunit b & 28,890 & 1.43 & 0.06 \\
\hline Transitional endoplasmic reticulum ATPase & 89,266 & 1.20 & 0.09 \\
\hline Ras-related protein Rab-7 & 23,475 & 1.19 & 0.14 \\
\hline UMP-CMP kinase & 22,208 & 1.38 & 0.19 \\
\hline
\end{tabular}

SE standard error

mx/SurvExpress) and TCGA (https://tcga-data.nci. nih.gov) [22, 25]. Most of these 20 candidate proteins exhibited higher mRNA levels in HCC tissues compared to normal liver tissues according to the GEPIA analysis (http://gepia.cancer-pku.cn/index.html) (Table 2). According to the OS analysis by the SurvExpress website, we further found that elevated mRNA expression of some candidates correlated with a poor prognosis in HCC patients, especially Ezrin, Rab18, ILEU (SERPINB1), PSD7 (PSMD7), TMED9, and Rab7 (Fig. 1b). Among these, Rab1a and Rab18 had previously been reported to promote HCC cell proliferation or act as a poor prognostic marker in HCC patients [26, 27]. Ezrin overexpression was associated with vascular invasion and a poor prognosis in patients with $\operatorname{HCC}[28,29]$. These results indicated the high credibility and applicability of our screening system to search for candidate biomarkers in HCC patients.

\section{mRNA expression level of TMED9 is significantly higher in HCC tumor tissues and is correlated with an advanced stage and poor patient prognoses}

Among these 20 candidate proteins, the role of TMED9, a protein secretion modulator, in HCC is largely unexplored. According to LC-MS/MS data, several peptides belonging to TMED9 were identified in patient samples (Additional file 1: Table S2). For instance, the LC-MS/MS fragment of R.QLVEQVEQIQK.E was identified as TMED9 HUMAN (Fig. 2). Thus, we hypothesized that TMED9 could be a putative prognostic biomarker in HCC. To further identify the potential prognostic value of TMED9 in HCC, we first analyzed its expression levels in 30 pre-neoplastic lesions (including 13 cirrhotic and 17 dysplastic samples) and 35 HCC samples (including 18 early and 17 advanced HCC) from the GSE6764 dataset of the GEO database. Significantly higher TMED9 transcripts were observed in tumors samples, especially in advanced HCC, than in pre-neoplastic lesions (Fig. 3a, b). In addition, we also examined TMED9 levels in paired N/T tissues in the GSE76311 dataset (Additional file 2: Figure S1a) and normal tissue versus tumor tissue in GSE102079 dataset (Additional file 2: Figure S1b). These results indicated significantly elevated TMED9 transcripts in malignant tissues. In addition to the GEO database, we then explored TMED9 in HCC via the GEPIA website (http://gepia.cancer-pku.cn/detail.php) based on the TCGA and GTEx databases. We also observed that TMED9 transcripts were more highly expressed in HCC tumor samples compared to normal liver tissues (Fig. 3c). Moreover, the prognostic value of TMED9 was also verified by GEPIA, and results showed that the OS of HCC patients was adversely affected by a higher TMED9 expression level ( $p=0.00084)$ (Fig. 3d). 
Table 2 mRNA expression levels of candidate proteins in hepatocellular carcinoma (HCC) tissues

\begin{tabular}{lcc}
\hline Protein ID/Gene name & Gepia T (TPM) & Gepia N (TPM) \\
\hline Ezrin/EZR & 21.5 & 18.64 \\
Elongation factor 1-gamma/EF1G & 721.42 & 356.44 \\
Aldehyde dehydrogenase family 7 member A1/ALDH7A1 & 112.76 & 74.83 \\
Calcium-binding mitochondrial carrier protein Aralar2/SLC25A13 & 33.92 & 34.11 \\
Ras-related protein Rab-18/RAB18 & 21.87 & 14.14 \\
Ras-related protein Rab-2A/RAB2A & 62.71 & 36 \\
Leukocyte elastase inhibitor (LEI)/SERPINB1 & 26.38 & 10.95 \\
26S proteasome non-ATPase regulatory subunit 7/PSMD7 & 42.62 & 28.45 \\
Ras-related protein Rab-1A/RAB1A & 84.1 & 65.7 \\
Proteasome subunit beta type 5 precursor/PSMB5 & 103.42 & 47.67 \\
Diablo homolog, mitochondrial precursor/DIABLO & 40.03 & 23.54 \\
4-trimethylaminobutyraldehyde dehydrogenase/ALDH9A1 & 52.42 & 48.4 \\
Calreticulin precursor/CALR & 813.78 & 337.32 \\
Ubiquitin-activating enzyme E1/UBA1 & 67.5 & 40.51 \\
Transmembrane emp24 domain-containing protein 9 precursor/TMED9 & 183.3 \\
Cytochrome c/CYC & 157.32 & 91.03 \\
ATP synthase subunit b/ATP5F1 & 161.42 & 75.33 \\
Transitional endoplasmic reticulum ATPase/VCP & 101.63 & 101.54 \\
Ras-related protein Rab-7/Rab7A & 87.32 & 60.53 \\
UMP-CMP kinase/CMPK1 & 56.7 & 58.97 \\
\hline T & 54.61 & \\
\end{tabular}

$T$ tumor tissue, $N$ normal tissue, TPM transcripts per million

\section{a TMED9 peptide: R.QLVEQVEQIQK.E}

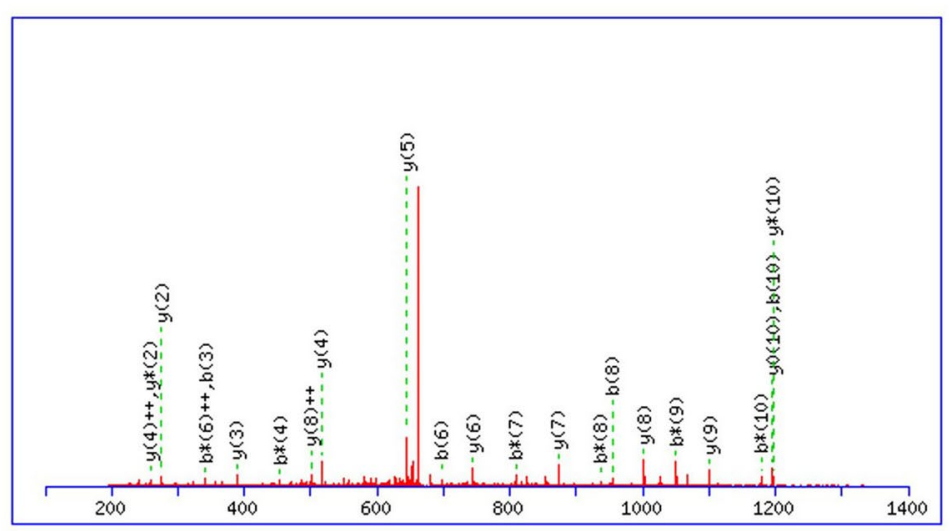

$\begin{array}{ccccc}\text { b \# } & \underline{\text { B ions }} & \underline{\text { Seq }} & \underline{\text { Y ions }} & \frac{\#}{11} \\ 1 & 120.0659 & \text { Q } & & 11 \\ 2 & 241.1499 & \text { L } & 1213.6187 & 10 \\ 3 & 341.2183 & \text { V } & 1100.5946 & 9 \\ 4 & 470.2609 & \text { E } & 1001.5262 & 8 \\ 5 & 598.3195 & \text { Q } & 872.4836 & 7 \\ 6 & 697.3879 & \text { V } & 744.4250 & 6 \\ 7 & 826.4305 & \text { E } & 645.3566 & 5 \\ 8 & 954.4891 & \text { Q } & 516.3140 & 4 \\ 9 & 1067.5732 & \text { I } & 388.2554 & 3 \\ 10 & 1195.6317 & \text { Q } & 275.1714 & 2 \\ 11 & & \text { K } & 147.1128 & 1\end{array}$

Fig. 2 Results of an LC-MS/MS analysis for TMED9. a Representative data showing the sequence of the trypsinized peptide, R.QLVEQVEQIQK.E, which was matched to TMED9 in hepatocellular carcinoma (HCC) patient samples. b Matching B-ions and Y-ions (red) fragments were recorded to identify the sequence of TMED9. The retained charge on the amino-terminal part of the peptide is shown as B-ions, and the retained charge on the carboxyl-terminal part of the peptide is Y-ions

Expression of TMED9 protein is significantly elevated in HCC tissues, and high TMED9 expression is correlated with vascular invasion and poor prognoses in HCC patients In addition to analyzing mRNA levels of TMED9 from datasets available online, we further verified protein levels of TMED9 by IHC staining from a Taiwanese HCC tissue array cohort. Representative examples of tumors showing overall negative (score 0 ), low (score 1 ), 
a

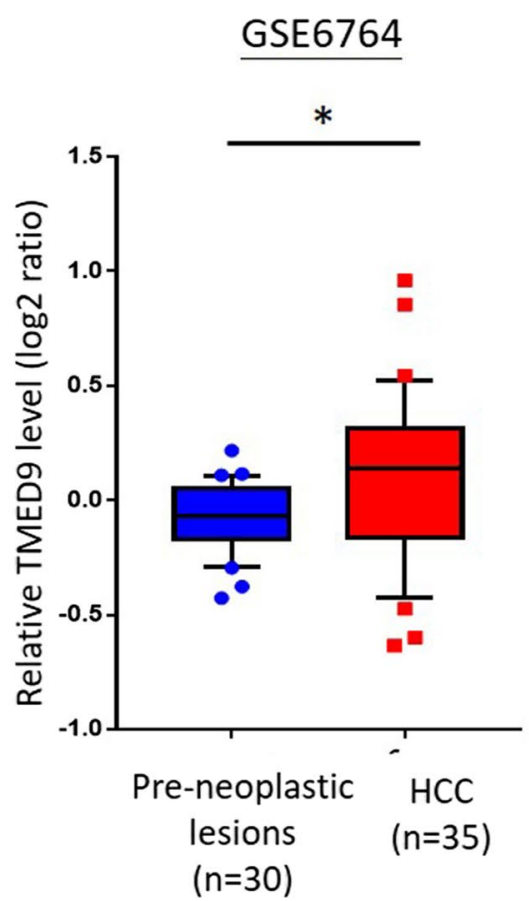

C

GEPIA

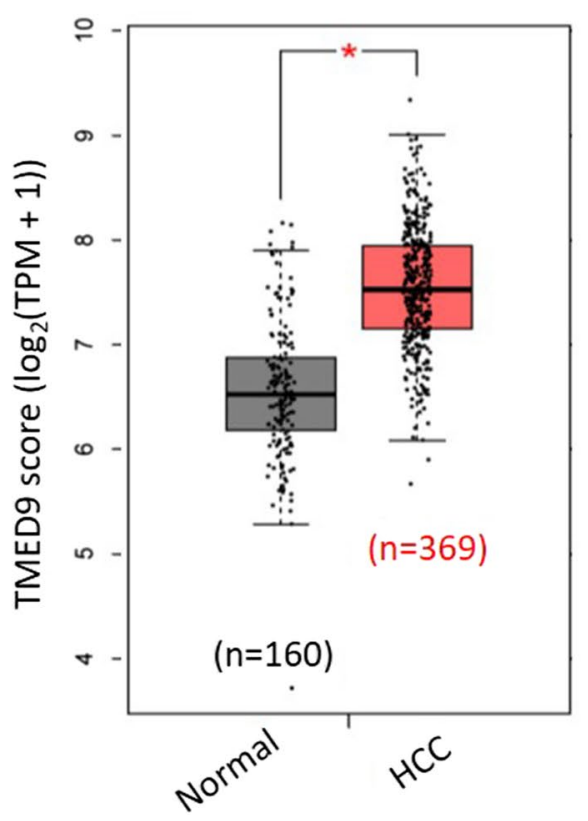

b GSE6764

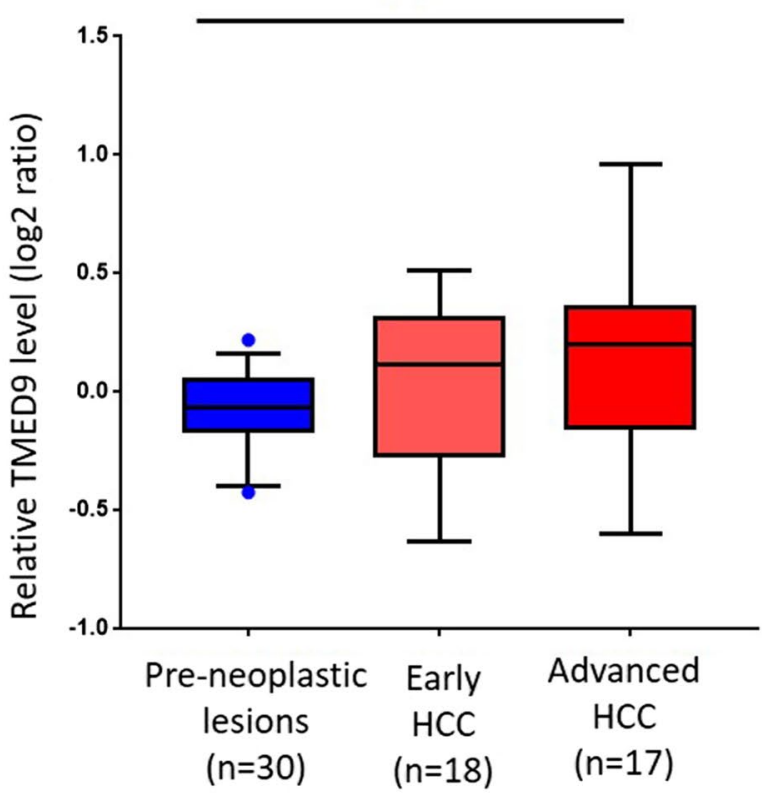

d

GEPIA

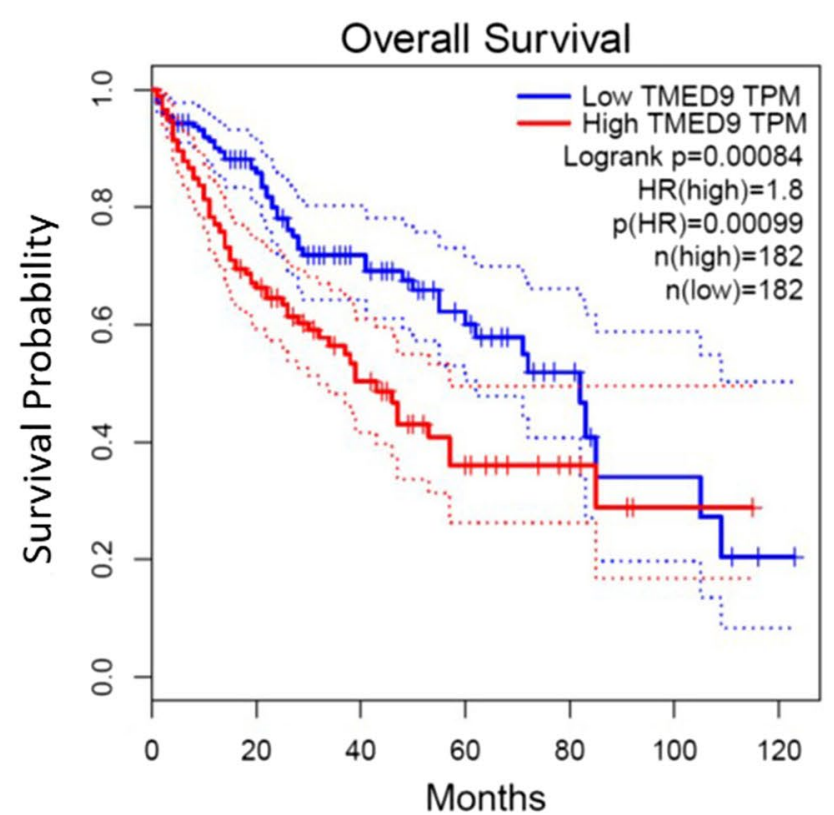

Fig. 3 In silico analysis of TMED9 expression in hepatocellular carcinoma (HCC). a, b Relative TMED9 mRNA levels (208757_at) in 30 pre-neoplastic lesions (including 13 cirrhotic samples and 17 dysplastic samples) and 35 HCC (including 18 early-stage and 17 advanced-stage HCC) samples from GSE6764 microarray datasets. Expression data were normalized to the median intensity of all probes and scaled to log2 transformation. $\mathbf{c}$ Expression levels of TMED9 transcripts in normal and HCC samples. $\mathbf{d}$ Kaplan-Meier curves for overall survival of patients with HCC, as categorized according to high or low expression of TMED9. The $p$ value indicates a comparison between patients with TMED $9^{\text {high }}$ and TMEDglow . Data in both $\mathbf{c}$ and $\mathbf{d}$ are from GEPIA online available databases (http://gepia.cancer-pku.cn/index.html) 
moderate (score 2), and high TMED9 (score 3) intensities are illustrated in Fig. 4a, and all positive cases revealed a diffuse cytoplasmic TMED9 distribution in cancer cells. According to our analysis, the score of TMED9 in HCC was significantly higher than that in corresponding noncancerous tissues $(p<0.0001)$ (Fig. $4 \mathrm{~b})$. We thus stratified patients into high- and low-TMED9 groups, and high expression levels of TMED9 were significantly correlated with worse OS ( $p=0.044$; Fig. $4 c)$ and DFS $(p=0.015$; Fig. 4d) in our recruited cohort.

Clinicopathological parameters of HCC patients are shown in Table 3. There were 182 patients, including 155 males and 27 females. Survival follow-up was available in all cases and ranged $1 \sim 172$ months (median, 52 months; mean, 60.02 months). Among these patients, 43 cases (23.6\%) experienced no recurrence, and 139 cases (76.4\%) had disease recurrence during the follow-up period. A Chi-squared analysis was conducted to explore relationships between selected clinicopathologic features and TMED9 expression. Table 3 shows that the TMED9 expression level was significantly correlated with hepatic vein invasion $(p=0.026)$, but not other clinicopathologic features such as the AFP level, HBV, liver cirrhosis, tumor size, and so on.

Moreover, we utilized a univariate analysis to examine the prognostic significance of clinicopathologic variables in our HCC cohort. In addition to TMED9 expression (hazard ratio (HR), 1.463; $p=0.047$ ), the tumor size (HR, 1.543; $p=0.023)$, portal vein invasion (HR, 3.463; $p<0.001)$, and hepatic vein invasion ( HR, 3.971; $p<0.001)$ were all shown to have adverse impacts on OS (Table 4). Furthermore, DFS was also adversely affected by high TMED9 expression (HR, 1.506; $p=0.017)$, portal vein invasion (HR, 3.662; $p<0.001)$, and hepatic vein invasion (HR, 11.333; $p<0.001$ ) (Table 5).

\section{TMED9 modulates the cell-proliferative, colony-forming, and invasive/migratory abilities of HCC cells}

To further investigate the functional role of TMED9 in HCC cells, we knocked-down TMED9 by two lentiviralbased shRNAs in highly invasive Mahlavu HCC cells (Fig. 5a) and examined the cell-invasive, proliferative, and colony-forming abilities of HCC cells. As shown in Fig. 5b, a significantly lower proliferative ability of HCC cells was observed in TMED9-knockdown groups than

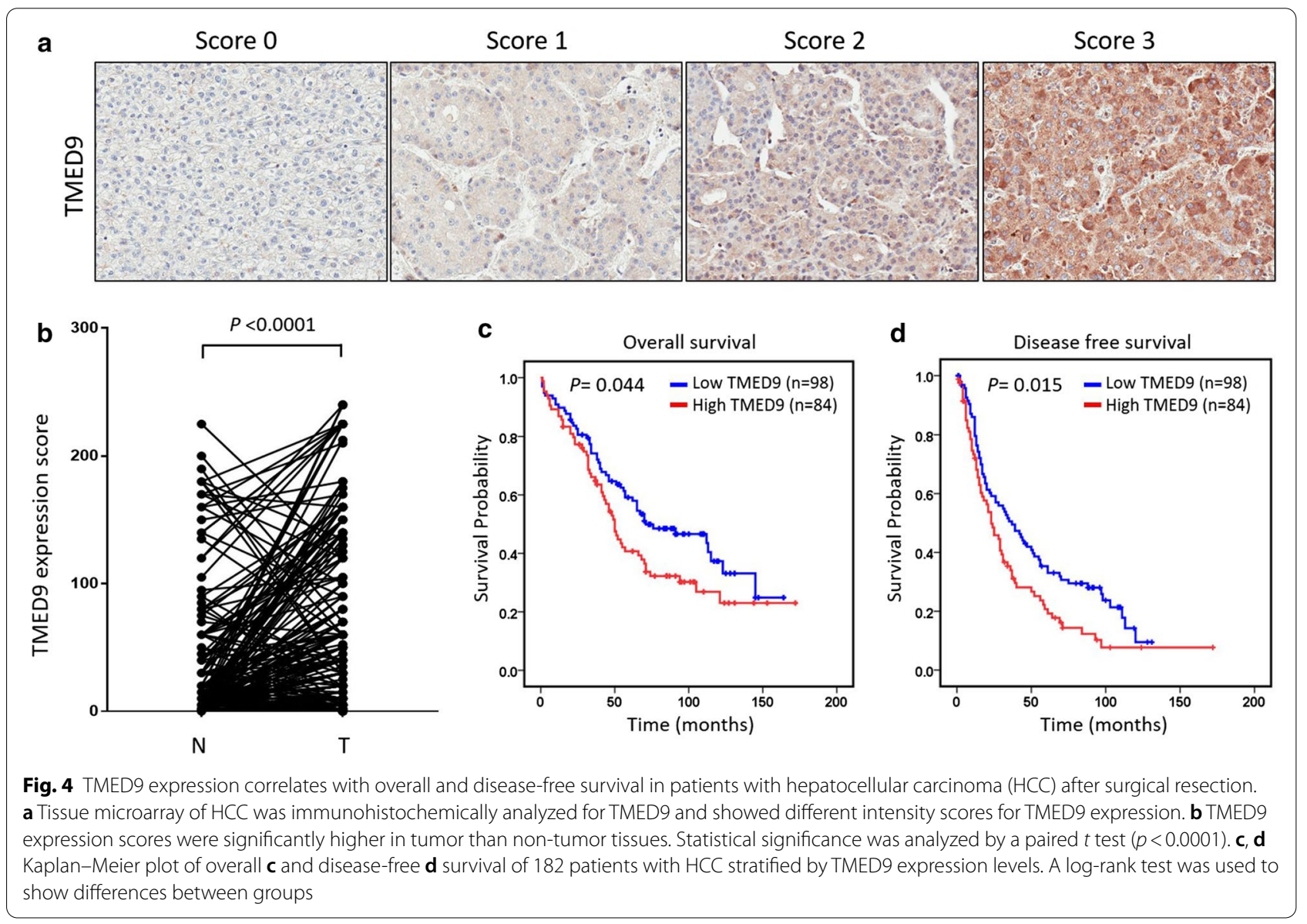


Table 3 Relationship between TMED9 expression and clinicopathological features in 182 patients with hepatocellular carcinoma (HCC)

\begin{tabular}{|c|c|c|c|}
\hline \multirow[t]{2}{*}{ Characteristic } & \multicolumn{2}{|c|}{ TMED9 expression } & \multirow[t]{2}{*}{$p$ value } \\
\hline & Low $(n=98)$ & High $(n=84)$ & \\
\hline Age, years (mean $\pm S D$ ) & $61.7 \pm 11.0$ & $60.85 \pm 13.65$ & \\
\hline \multicolumn{4}{|l|}{ Gender } \\
\hline Male & 83 & 72 & 0.847 \\
\hline Female & 15 & 12 & \\
\hline \multicolumn{4}{|l|}{ AFP $(n g / m L)$} \\
\hline$<400$ & 79 & 63 & 0.293 \\
\hline$\geq 400$ & 17 & 20 & \\
\hline Unknown & 2 & 1 & \\
\hline \multicolumn{4}{|l|}{ Stage } \\
\hline $1+\|$ & 72 & 57 & 0.406 \\
\hline | || & 26 & 27 & \\
\hline \multicolumn{4}{|l|}{ HBV } \\
\hline Negative & 35 & 26 & 0.407 \\
\hline Positive & 60 & 58 & \\
\hline Unknown & 3 & 0 & \\
\hline \multicolumn{4}{|l|}{$\mathrm{HCV}$} \\
\hline Negative & 63 & 67 & 0.024 \\
\hline Positive & 33 & 16 & \\
\hline Unknown & 2 & 1 & \\
\hline \multicolumn{4}{|l|}{ Recurrence status } \\
\hline No & 26 & 17 & 0.319 \\
\hline Yes & 72 & 67 & \\
\hline \multicolumn{4}{|l|}{ Liver cirrhosis } \\
\hline No & 51 & 45 & 0.872 \\
\hline Yes & 41 & 38 & \\
\hline Unknown & 6 & 1 & \\
\hline \multicolumn{4}{|l|}{ Tumor size (cm) } \\
\hline$<5$ & 57 & 47 & 0.764 \\
\hline$>5$ & 41 & 37 & \\
\hline \multicolumn{4}{|l|}{ Tumor numbers } \\
\hline Solitary & 57 & 48 & 0.89 \\
\hline Multiple & 41 & 36 & \\
\hline \multicolumn{4}{|l|}{ Hepatic vein invasion } \\
\hline No & 95 & 74 & 0.026 \\
\hline Yes & 2 & 8 & \\
\hline Unknown & 1 & 2 & \\
\hline \multicolumn{4}{|l|}{ Portal vein invasion } \\
\hline No & 89 & 72 & 0.186 \\
\hline Yes & 7 & 11 & \\
\hline Unknown & 2 & 1 & \\
\hline
\end{tabular}

$S D$ standard deviation, $A F P$ alpha fetoprotein, $H B V$ hepatitis $B$ virus, $H C V$ hepatitis $C$ virus
Table 4 Cox univariate and multivariate regression analysis of prognostic factors and TMED9 expression for overall survival (OS) in 182 hepatocellular carcinoma (HCC) patients

\begin{tabular}{|c|c|c|c|}
\hline Variables & Comparison & $\mathrm{HR}(95 \% \mathrm{Cl})$ & $P$ value \\
\hline \multicolumn{4}{|c|}{ Cox Univariate Analysis (OS) } \\
\hline Age & $<61$ years $; \geq 61$ years & $1.233(0.836-1.818)$ & 0.292 \\
\hline Gender & Female; male & $0.695(0.397-1.218)$ & 0.204 \\
\hline Stage & l; II; III & $1.255(0.951-1.657)$ & 0.109 \\
\hline AFP & $<400 \mathrm{ng} / \mathrm{mL} ; \geq 400 \mathrm{ng} / \mathrm{mL}$ & $1.398(0.887-2.203)$ & 0.149 \\
\hline HBV & Negative; positive & $1.111(0.763-1.617)$ & 0.584 \\
\hline $\mathrm{HCV}$ & Negative; positive & $0.917(0.603-1.396)$ & 0.687 \\
\hline $\begin{array}{l}\text { Tumor } \\
\text { size }\end{array}$ & $\leq 5 \mathrm{~cm} ;>5 \mathrm{~cm}$ & $1.543(1.061-2.244)$ & $0.023^{*}$ \\
\hline $\begin{array}{l}\text { Cut mar- } \\
\text { gin }\end{array}$ & $<1 \mathrm{~cm} ;>1 \mathrm{~cm}$ & $0.728(0.488-1.086)$ & 0.120 \\
\hline PVI & No; yes & $3.463(1.993-6.014)$ & $0.000^{* * *}$ \\
\hline $\mathrm{HVI}$ & No; yes & $3.971(1.980-7.964)$ & $0.000^{* * *}$ \\
\hline TMED9 & Low; high & $1.463(1.005-2.128)$ & $0.047^{*}$ \\
\hline \multicolumn{4}{|c|}{ Cox Multivariate Analysis (OS) } \\
\hline $\begin{array}{l}\text { Tumor } \\
\text { size }\end{array}$ & $\leq 5 \mathrm{~cm} ;>5 \mathrm{~cm}$ & $1.323(0.883-1.981)$ & 0.175 \\
\hline PVI & No; yes & $2.444(1.216-4.911)$ & $0.012^{*}$ \\
\hline $\mathrm{HVI}$ & No; yes & $1.580(0.656-3.809)$ & 0.308 \\
\hline TMED9 & Low; high & $1.249(0.831-1.876)$ & 0.285 \\
\hline
\end{tabular}

Table 5 Cox univariate and multivariate regression analysis of prognostic factors and TMED9 expression for disease-free survival (DFS) in 182 hepatocellular carcinoma (HCC) patients

\begin{tabular}{|c|c|c|c|}
\hline Variables & Comparison & HR (95\% Cl) & $P$ value \\
\hline \multicolumn{4}{|c|}{ Cox Univariate Analysis (DFS) } \\
\hline Age & $<61$ years $; \geq 61$ years & $0.814(0.583-1.138)$ & 0.229 \\
\hline Gender & Female; male & $0.866(0.549-1.366)$ & 0.536 \\
\hline Stage & I; II; III & $1.248(0.977-1.594)$ & 0.076 \\
\hline AFP & $<400 \mathrm{ng} / \mathrm{mL} ; \geq 400 \mathrm{ng} / \mathrm{mL}$ & $1.159(0.753-1.782)$ & 0.503 \\
\hline HBV & Negative; positive & $1.262(0.897-1.777)$ & 0.182 \\
\hline $\mathrm{HCV}$ & Negative; positive & $1.090(0.753-1.577)$ & 0.649 \\
\hline Tumor size & $\leq 5 \mathrm{~cm} ;>5 \mathrm{~cm}$ & $1.371(0.979-1.920)$ & 0.066 \\
\hline Cut margin & $<1 \mathrm{~cm} ;>1 \mathrm{~cm}$ & $0.686(0.481-0.979)$ & $0.038^{*}$ \\
\hline PVI & No; yes & $3.662(2.043-6.567)$ & $0.000^{* * *}$ \\
\hline $\mathrm{HVI}$ & No; yes & $\begin{array}{l}11.333(5.191- \\
24.138)\end{array}$ & $0.000^{* * *}$ \\
\hline TMED9 & Low; high & $1.506(1.076-2.107)$ & $0.017^{*}$ \\
\hline \multicolumn{4}{|c|}{ Cox Multivariate Analysis (DFS) } \\
\hline Cut margin & $\leq 1 \mathrm{~cm} ;>1 \mathrm{~cm}$ & $0.770(0.525-1.129)$ & 0.181 \\
\hline PVI & No; yes & $2.438(1.268-4.688)$ & $0.008^{* *}$ \\
\hline $\mathrm{HVI}$ & No; yes & $\begin{array}{l}8.273(3.531- \\
19.381)\end{array}$ & $<0.001^{* * *}$ \\
\hline TMED9 & Low; high & $1.173(0.807-1.703)$ & 0.403 \\
\hline
\end{tabular}

All terms are defined in the legend to Table 4 


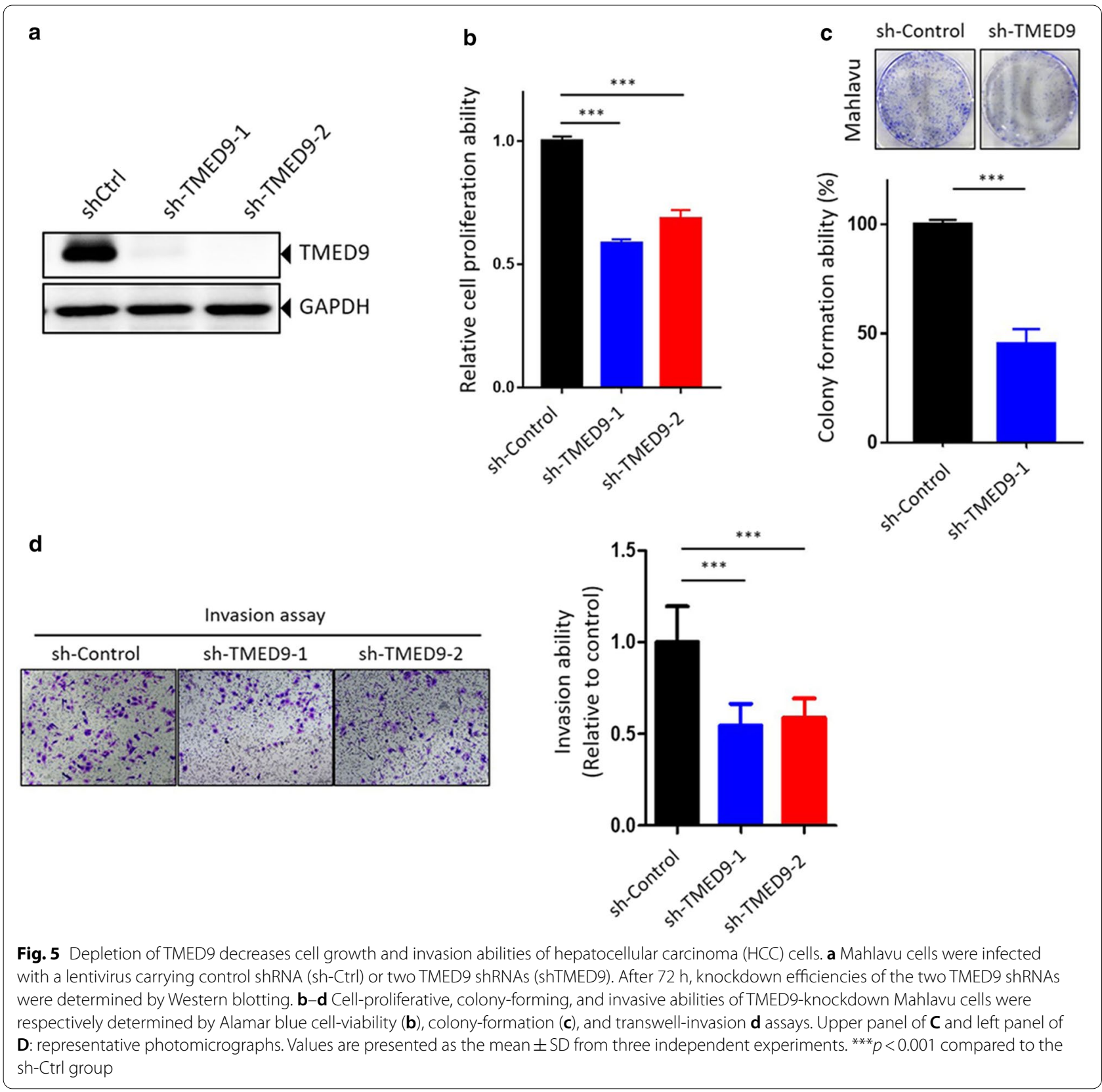

in control groups. Moreover, we examined the effect of TMED9 on the long-term growth (10 days) of Mahlavu cells using a colony-formation assay and found that the number of colonies was reduced following TMED9 knockdown (Fig. 5c). Furthermore, results from the transwell invasion assay showed that significant attenuation of the invasive ability was observed in TMED9-depleted HCC cells (Fig. 5d). In comparison to Mahlavu cells, we ectopically expressed TMED9 in low-invasive HCC36 cells (Additional file 2: Figure S2a) and observed that overexpression of TMED9 significantly increased cell proliferation (Additional file 2: Figure S2b) and motility (Additional file 2: Figure S2c). These results indicated that TMED9 may be deeply involved in HCC progression, and suggested that targeting TMED9 might be a potential therapeutic strategy for arresting $\mathrm{HCC}$ progression.

\section{Discussion}

The main finding of the present study was to identify TMED9, one of the transport proteins located in the endoplasmic reticulum (ER) and Golgi network, as a prognostic biomarker of HCC progression. Reliable mass 
spectrometry-based analyses have been used for drug discovery, metabolomic analysis, and cancer biomarker investigations [30, 31]. Herein, we interpreted LC-MS/MS data to identify elevated candidate proteins in HCC tissues (Table 1) for diagnostic and prognostic predictions in HCC. Similar to TMED9, one of the candidate markers, aldehyde dehydrogenase 7 family member A1 (ALDH7A1), was previously reported to be more highly expressed in HCC tissues than in non-tumorous liver tissues, but its expression in tumor tissues was not correlated with OS, recurrence, or microvascular invasion [32]. Although some candidate markers, such as Rab1, Rab18, and Ezrin which are elevated in HCC, were reported to promote HCC progression [26-29], the oncogenic or tumor-suppressive roles of other candidate proteins we found in HCC tissues remain unclear. For example, Rab7 expression regulated the migratory ability of lung cancer H1299 cells through Ras-related C3 botulinum toxin substrate 1 (RAC1) and vimentin [33]. In MCF-7 breast cancer cells, Rab7 is responsible for Akt survival signal maintenance to promote cells anoikis resistance [34]. In contrast, Rab7 was reported to be a tumor suppressor in prostate cancer based on the fact that it inhibited ligand-induced c-Met signaling [35]. In addition to Rab7, it was revealed that overexpression of serine protease inhibitor B1 (SERPINB1; also known as ILEU) promotes the motility of oral squamous cell carcinoma [36], but the epigenetic suppression of SERPINB1 predicts a poorer prognosis in prostate cancer patients [37]. Thus, further investigations of the roles of candidate proteins which we found in HCC tissues are still needed. After a literature review and our preliminary in silico analysis, we found that TMED9 showed a poor prognostic impact on HCC, but has rarely been investigated in HCC.

TMED9 belongs to the transmembrane emp24 domain-containing protein (TMED)/p24 family, including TMED1-7 and TMED9-11 which are responsible for selecting cargo in the processing ER-Golgi network of proteins (secretory pathway) and innate immune signaling $[38,39]$. Given that a huge diversity exists among the proteins of this family, TMED proteins can influence the stability of each other while forming monomers or dynamic complexes [40, 41]. Abnormalities in the controlled transport of proteins in the secretory pathway contribute to diseases such as cancer. For example, a reduction in TMED2 was reported to increase the possibility of liver tumorigenesis [39]. In contrast, elevated levels of TMED2 were observed in patients with ovarian and breast cancers. TMED2 was identified as a promoter of cell proliferation and migration in ovarian cancer cells through activating Akt and as a poor prognostic factor in patients with breast cancer [42, 43]. TMED3 was reported to be an oncoprotein in $\mathrm{HCC}$, prostate cancers, breast cancers, and kidney cancers. [44-47]. For example, TMED3 enhanced cell migration by activating interleukin
(IL)-11/signal transducer and activator of transcription 3 (STAT3) signaling and promoted HCC progression [47]. TMED3 was also reported to promote proliferation and motility of breast cancer cells by activating $\mathrm{WNT} / \beta$ catenin pathway [48]. In contrast, TMED3 was identified as a tumor suppressor in colon cancer and proposed to inhibit metastasis by repressing TMED9. TMED3 depletion can trigger a TMED9-induced metastasis via inducing transforming growth factor (TGF)- $\alpha$ secretion and upregulating CNIH4/TGF- $\alpha /$ GLI1 signaling [49]. According to those results, the malignant properties of TMED2 and TMED3 in cancer are cell type-specific.

TMED2 and TMED3 were respectively reported to be a tumor suppressor and an oncogene in $\operatorname{HCC}[39,47]$. However, the oncogenic role of TMED9 was only identified in colon cancer [49], but not in other cancer types. In this study, we first reported the prognostic and functional roles of TMED9 in HCC. We further dissected interacting neighbors of TMED9 using the STRING database (https:// string-db.org/) and found ten potential TMED9-associated genes, including TMED10, TMED2, TMED3, TMED7, STX5, KDELR2, SEC22B, SURF4, GORASP1, and NAGLU (Fig. 6a), which are necessary for Golgi vesicle transport and related vesicle-trafficking functions (Fig. 6b). We then verified correlations of TMED9 with these genes in 373 HCC human samples using the cBioportal platform and observed that TMED9 expression was only significantly correlated with STX5, TMED3, and SURF4 (Fig. 6c). Furthermore, TCGA database showed that a poorer prognosis was observed in HCC patients with high levels of TMED9 and TMED3 in tumors compared to patients with low levels of TMED9 and TMED3 in tumors (Fig. 6d). Opposite roles of TMED9 and TMED3 in regulating the progression of colon cancer were reported [49]. Although the roles of TMED9 and TMED3 in HCC differed from those in colon cancer, how the interaction between TMED9 and TMED3 promotes HCC progression remains for further evaluation. Herein, we first evaluated the effect of TMED9 knockdown on TMED9and TMED3-modulated signaling molecules which have been reported in other cancer types [48, 49]. We observed that TMED9 knockdown in Mahlavu cells decreased expression of $\beta$-catenin and GLI1, phosphorylation of ERK and STAT3, and secretion of TGF- $\alpha$ compared to control cells (Fig. 6e). In comparison, $\beta$-catenin, GLI1, p-ERK, p-STAT3, and secreted TGF- $\alpha$ were all upregulated in TMED9-overexpressed HCC36 cells (Fig. 6f). These results suggested that $\mathrm{CNIH} 4 / \mathrm{TGF}-\alpha / \mathrm{GLI} 1$ and $\mathrm{WNT} / \beta$-catenin pathways might be involved in TMED9-induced HCC progression and these issues should be further investigated in future research.

Our current study is not without limitations. First, since the HCC samples were collected from 1990 to 2006 in our study, the examination of $\mathrm{HBV} / \mathrm{HCV}$ viral levels was not been determined and no anti-viral therapies were available at 


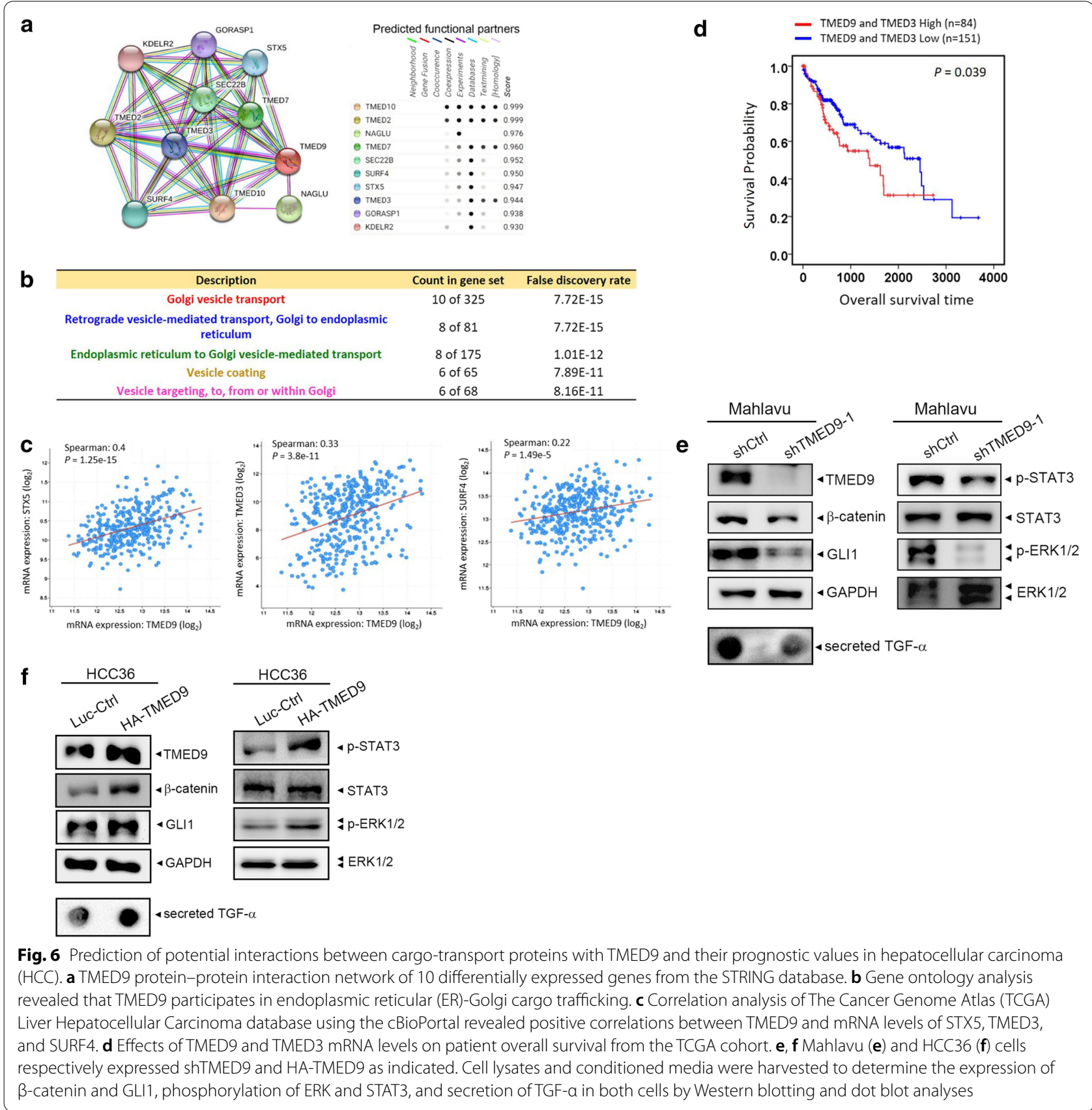

that period. Thus, we can't analyze whether the baseline viral level affecting HCC patient outcome. Moreover, the sample size of the current study was still not large enough and might lead to a limited statistical impact on the accuracy and precision of the results. For example, TMED9 expression level has a negative impact on OS and DFS from univariate, but not multivariate analysis. Larger HCC cohort should be further recruited to confirm this result in future. Furthermore, the clinical data and follow-up conditions were prospectively collected. Even we did our best to collect detail clinical information, there were still few patients lacking the status of cirrhosis or hepatic/portal vein invasion.

\section{Conclusions}

According to our study, TMED9 is present in freshfrozen HCC tissues and can be successfully detected by an LC-MS/MS analysis. Using this technology, we first identified that TMED9 could be a valuable prognostic biomarker for $\mathrm{HCC}$ and revealed the functional role 
of TMED9 in HCC cells. Whether TMED9 can interact with TMED3 or other cargo-transport proteins to promote HCC cell proliferation and motility needs be further addressed; yet our present findings strongly support the targeting of TMED9 as a novel strategy for HCC treatment.

\begin{abstract}
Abbreviations
ABC: Ammonium bicarbonate; ACN: Acetonitrile; DFS: Disease-free survival; DTT: Dithiothreitol; GEO: Gene Expression Omnibus; GEPIA: Gene Expression Profiling Interactive Analysis; GTEx: Genotype-Tissue Expression; HCC: Hepatocellular carcinoma; HR: Hazard ratio; IHC: Immunohistochemical/ immunohistochemistry; LC-MS/MS: Liquid chromatography-tandem mass spectrometry; OCT: Optimum cutting temperature; OS: Overall survival; TCGA :The Cancer Genome Atlas; TMED9: Transmembrane P24 trafficking protein 9; TPM: Transcripts per million.
\end{abstract}

\section{Supplementary Information}

The online version contains supplementary material available at https://doi. org/10.1186/s12929-021-00727-5.

Additional file 1: Table S1. List of protein score ratio $(<1)$ of hepatocellular carcinoma (HCC) tumor versus normal samples. Table S2. Matched TMED9 peptides in hepatocellular carcinoma (HCC) tissues.

Additional file 2: Figure S1. Expression of TMED9 transcripts in paired adjacent (GSE76311, probe: TC05001018.hg.1; $\mathbf{a}$ and unpaired normal and tumor tissues (GSE102079, probe: 208757 at: $\mathbf{b}$ derived from patients with hepatocellular carcinoma (HCC). Figure S2. TMED9 overexpression promotes cell growth and migration of HCC 36 cells. a HCC 36 cells were infected with a lentivirus carrying control vector or HA-TMED9. After $72 \mathrm{~h}$, the expression of TMED 9 was determined by Western blotting. b, c Cellproliferative $\mathbf{b}$ and migratory $\mathbf{c}$ abilities of $\mathrm{HCC} 36$ cells expressing control vector or HA-TMED9. Values are presented as the mean \pm SD from three independent experiments. ${ }^{*} p<0.05 ;{ }^{* *} p<0.01$ versus the vehicle control group.

\section{Acknowledgments}

We thank Ms. Tracy Tsai for her assistance with the immunohistochemical work. We also thank Dr. Hao-Jan Lei for providing the HCC patient samples.

\section{Authors' contributions}

$\mathrm{M}-\mathrm{H}, \mathrm{M}-\mathrm{HC}, \mathrm{C}-\mathrm{NY}, \mathrm{Y}-\mathrm{CY}$, and $\mathrm{M}-\mathrm{HC}$ designed and conceived the study; $\mathrm{Y}-\mathrm{CY}$, $\mathrm{T}-\mathrm{CL}, \mathrm{Y}-\mathrm{HJ}$, and $\mathrm{W}-\mathrm{MC}$ performed the research; $\mathrm{M}-\mathrm{CT}$ and $\mathrm{S}-\mathrm{MJ}$ participated in the results discussion and technical support; $Y-C Y, M-H C, T-C L$, and $\mathrm{M}-\mathrm{H}$ wrote the paper. All authors read and approved the final manuscript.

\section{Funding}

This study was supported by grant AS-SUMMIT-108 from Academia Sinica (to M. Hsiao).

\section{Availability of data and materials}

All data used during the current study are available from the corresponding author on reasonable request.

\section{Declarations}

\section{Ethical approval and consent to participate}

The procedures for collecting patients were approved by the Ethics Committee of Taipei Veterans General Hospital (201010021IC). This study was supported by the Taipei Medical University Research Center of Cancer Translational Medicine from The Featured Areas Research Center Program within the framework of the Higher Education Sprout Project by the Ministry of Education in Taiwan (to M.-H. Chien).

\section{Consent for publication}

Not applicable.

\section{Competing interests}

The authors declare that they have no conflicts of interest.

\section{Author details}

'Department of Medical Research, Tungs'Taichung Metro Harbor Hospital, Taichung, Taiwan. ${ }^{2}$ Graduate Institute of Clinical Medicine, College of Medicine, Taipei Medical University, Taipei 11031, Taiwan. ${ }^{3}$ Genomics Research Center, Academia Sinica, 128 Academia Road, Section 2, Nankang, Taipei 11529, Taiwan. ${ }^{4}$ Pulmonary Research Center, Wan Fang Hospital, Taipei Medical University, Taipei, Taiwan. ${ }^{5}$ Traditional Herbal Medicine Research Center, Taipei Medical University Hospital, Taipei, Taiwan. ${ }^{6}$ TMU Research Center of Cancer Translational Medicine, Taipei Medical University, Taipei, Taiwan. ${ }^{7}$ Division of Pulmonary Medicine, Department of Internal Medicine, Wan Fang Hospital, Taipei Medical University, Taipei, Taiwan. ${ }^{8}$ School of Oral Hygiene, College of Oral Medicine, Taipei Medical University, Taipei, Taiwan. ${ }^{9}$ Department of Pathology, Chang Gung Memorial Hospital, Chang Gung University, Taoyuan, Taiwan. ${ }^{10}$ Department of Oncology, Taipei Veterans General Hospital and School of Medicine, National Yang-Ming University, Taipei 112, Taiwan. ${ }^{11}$ School of Medicine, National Yang-Ming University, Taipei, Taiwan. ${ }^{12}$ Department of General Surgery and Liver Research Center, Linkou Branch, Chang Gung Memorial Hospital, Chang Gung University, Taoyuan 333, Taiwan,

${ }^{13}$ Department of Biochemistry, Kaohsiung Medical University, Kaohsiung, Taiwan. ${ }^{14}$ Graduate Institute of Cancer Biology and Drug Discovery, College of Medical Science and Technology, Taipei Medical University, Taipei, Taiwan.

Received: 7 October 2020 Accepted: 14 April 2021

Published online: 22 April 2021

\section{References}

1. Forner A, Reig M, Bruix J. Hepatocellular carcinoma. Lancet. 2018;391:1301-14.

2. Balogh J, Victor D 3rd, Asham EH, Burroughs SG, Boktour M, Saharia A Li X, Ghobrial RM, Monsour HP Jr. Hepatocellular carcinoma: a review. J Hepatocell Carcinoma. 2016:3:41-53.

3. Batey RG, Burns T, Benson RJ, Byth K. Alcohol consumption and the risk of cirrhosis. Med J Aust. 1992;156:413-6.

4. Rinella ME. Nonalcoholic fatty liver disease: a systematic review. JAMA. 2015;313:2263-73.

5. Ferlay J, Shin HR, Bray F, Forman D, Mathers C, Parkin DM. Estimates of worldwide burden of cancer in 2008: GLOBOCAN 2008. Int J Cancer. 2010:127:2893-917.

6. Yang JD, Hainaut P, Gores GJ, Amadou A, Plymoth A, Roberts LR. A global view of hepatocellular carcinoma: trends, risk, prevention and management. Nat Rev Gastroenterol Hepatol. 2019;16:589-604.

7. Heimbach JK, Kulik LM, Finn RS, Sirlin CB, Abecassis MM, Roberts LR, Zhu AX, Murad MH, Marrero JA. AASLD guidelines for the treatment of hepatocellular carcinoma. Hepatology. 2018;67:358-80.

8. Gosalia AJ, Martin P, Jones PD. Advances and future directions in the treatment of hepatocellular carcinoma. Gastroenterol Hepatol (N Y). 2017:13:398-410.

9. Lee YJ, Lee JM, Lee JS, Lee HY, Park BH, Kim YH, Han JK, Choi BI. Hepatocellular carcinoma: diagnostic performance of multidetector CT and MR imaging-a systematic review and meta-analysis. Radiology. 2015:275:97-109.

10. Oka H, Tamori A, Kuroki T, Kobayashi K, Yamamoto S. Prospective study of alpha-fetoprotein in cirrhotic patients monitored for development of hepatocellular carcinoma. Hepatology. 1994;19:61-6.

11. Sallam RM. Proteomics in cancer biomarkers discovery: challenges and applications. Dis Markers. 2015;2015:321370.

12. Marquardt C, TolstikT, Bielecki C, Kaufmann R, Crecelius AC, Schubert US, Settmacher U, Stallmach A, Dirsch O. MALDI imaging-based classification of hepatocellular carcinoma and non-malignant lesions in fibrotic liver tissue. Z Gastroenterol. 2015;53:33-9.

13. Zhang JY, Liang R, Wei JZ, Ye JX, He Q, Chunling Y, Ye JZ, Li YQ, Liu ZH, Lin Y. Identification of candidate biomarkers in malignant ascites from patients 
with hepatocellular carcinoma by iTRAQ-based quantitative proteomic analysis. Biomed Res Int. 2018. https://doi.org/10.1155/2018/5484976.

14. Baniasadi H, Gowda GAN, Gu HW, Zeng A, Zhuang S, Skill N, Maluccio M, Raftery D. Targeted metabolic profiling of hepatocellular carcinoma and hepatitis C using LC-MS/MS. Electrophoresis. 2013;34:2910-7.

15. Ahn YH, Shin PM, Oh NR, Park GW, Kim H, Yoo JS. A lectin-coupled, targeted proteomic mass spectrometry (MRM MS) platform for identification of multiple liver cancer biomarkers in human plasma. J Proteomics. 2012;75:5507-15.

16. Chen XL, Zhou L, Yang J, Shen FK, Zhao SP, Wang YL. Hepatocellular carcinoma-associated protein markers investigated by MALDI-TOF MS. Mol Med Rep. 2010;3:589-96.

17. Bairoch A, Apweiler R. The SWISS-PROT protein sequence data bank and its supplement TrEMBL in 1999. Nucleic Acids Res. 1999;27:49-54.

18. Wurmbach E, Chen YB, Khitrov G, Zhang W, Roayaie S, Schwartz M, Fie I, Thung S, Mazzaferro V, Bruix J, et al. Genome-wide molecular profiles of HCV-induced dysplasia and hepatocellular carcinoma. Hepatology. 2007:45:938-47.

19. Chaisaingmongkol J, Budhu A, Dang H, Rabibhadana S, Pupacdi B, Kwon SM, Forgues M, Pomyen Y, Bhudhisawasdi V, Lertprasertsuke N, et al. Common molecular subtypes among asian hepatocellular carcinoma and cholangiocarcinoma. Cancer Cell. 2017;32(57-70):e53.

20. Chiyonobu N, Shimada S, Akiyama Y, Mogushi K, Itoh M, Akahoshi K, Matsumura S, Ogawa K, Ono H, Mitsunori Y, et al. Fatty acid binding protein 4 (FABP4) overexpression in intratumoral hepatic stellate cells within hepatocellular carcinoma with metabolic risk factors. Am J Pathol. 2018;188:1213-24

21. Tang Z, Li C, Kang B, Gao G, Li C, Zhang Z. GEPIA: a web server for cancer and normal gene expression profiling and interactive analyses. Nucleic Acids Res. 2017:45:W98-102.

22. Goldman MJ, Craft B, Hastie M, Repecka K, McDade F, Kamath A, Banerjee A, Luo YH, Rogers D, Brooks AN, et al. Visualizing and interpreting cancer genomics data via the Xena platform. Nat Biotechnol. 2020;38:675-8.

23. Chen MH, Jan YH, Chang PM, Chuang YJ, Yeh YC, Lei HJ, Hsiao M, Huang SF, Huang CY, Chau GY. Expression of GOLM1 correlates with prognosis in human hepatocellular carcinoma. Ann Surg Oncol. 2013;20:5616-24.

24. Yang YC, Chien MH, Liu HY, Chang YC, Chen CK, Lee WJ, Kuo TC, Hsiao M, Hua KT, Cheng TY. Nuclear translocation of PKM2/AMPK complex sustains cancer stem cell populations under glucose restriction stress. Cancer Lett. 2018:421:28-40.

25. Aguirre-Gamboa R, Gomez-Rueda H, Martinez-Ledesma E, Martinez-Torteya A, Chacolla-Huaringa R, Rodriguez-Barrientos A, Tamez-Pena JG, Trevino V. SurvExpress: an online biomarker validation tool and database for cancer gene expression data using survival analysis. PLoS ONE. 2013;8:e74250

26. Dong Z, Qi R, Guo X, Zhao X, LiY, Zeng Z, Bai W, Chang X, Hao L, Chen Y, et al. MiR-223 modulates hepatocellular carcinoma cell proliferation through promoting apoptosis via the Rab1-mediated mTOR activation. Biochem Biophys Res Commun. 2017:483:630-7.

27. Gong T, Zhou B, Liu M, Chen X, Huang S, Xu Y, Luo R, Chen Z. RAB18 promotes proliferation and metastasis in hepatocellular carcinoma. Am J Transl Res. 2019;11:1009-19.

28. Yeh CN, Pang ST, Chen TW, Wu RC, Weng WH, Chen MF. Expression of ezrin is associated with invasion and dedifferentiation of hepatitis B related hepatocellular carcinoma. BMC Cancer. 2009;9:233.

29. Okamura D, Ohtsuka M, Kimura F, Shimizu H, Yoshidome H, Kato A, Miyazaki M. Ezrin expression is associated with hepatocellular carcinoma possibly derived from progenitor cells and early recurrence after surgical resection. Mod Pathol. 2008:21:847-55.

30. Cazares LH, Troyer D, Mendrinos S, Lance RA, Nyalwidhe JO, Beydoun HA, Clements MA, Drake RR, Semmes OJ. Imaging mass spectrometry of a specific fragment of mitogen-activated protein kinase/extracellular signalregulated kinase kinase kinase 2 discriminates cancer from uninvolved prostate tissue. Clin Cancer Res. 2009;15:5541-51.

31. Djidja MC, Francese S, Loadman PM, Sutton CW, Scriven P, Claude E, Snel MF, Franck J, Salzet M, Clench MR. Detergent addition to tryptic digests and ion mobility separation prior to MS/MS improves peptide yield and protein identification for in situ proteomic investigation of frozen and formalin-fixed paraffin-embedded adenocarcinoma tissue sections. Proteomics. 2009;9:2750-63.

32. Pommergaard HC, Hasselby JP, Willemoe GL, Ralbovska A, Rostved AA, Rasmussen A, Schultz NA, Hillingsø J, Nørgaard Larsen P, Kugler JM. Peroxisome proliferator-activated receptor activity correlates with poor survival in patients resected for hepatocellular carcinoma. J Hepatobiliary Pancreat Sci. 2020. https://doi.org/10.1002/jhbp.745.

33. Margiotta A, Progida C, Bakke O, Bucci C. Rab7a regulates cell migration through Rac1 and vimentin. Biochim Biophys Acta Mol Cell Res. 2017;1864:367-81.

34. Wang T, Zhang M, Ma Z, Guo K, Tergaonkar V, Zeng Q, Hong W. A role of Rab7 in stabilizing EGFR-Her2 and in sustaining Akt survival signal. J Cell Physiol. 2012;227:2788-97.

35. Steffan JJ, Dykes SS, Coleman DT, Adams LK, Rogers D, Carroll JL, Williams BJ, Cardelli JA. Supporting a role for the GTPase Rab7 in prostate cancer progression. PLoS ONE. 2014;9:e87882.

36. Tseng MY, Liu SY, Chen HR, Wu YJ, Chiu CC, Chan PT, Chiang WF, Liu YC, Lu CY, Jou YS, et al. Serine protease inhibitor (SERPIN) B1 promotes oral cancer cell motility and is over-expressed in invasive oral squamous cell carcinoma. Oral Oncol. 2009;45:771-6.

37. Lerman I, Ma X, Seger C, Maolake A, Garcia-Hernandez ML, Rangel-Moreno J, Ackerman J, Nastiuk KL, Susiarjo M, Hammes SR. Epigenetic suppression of SERPINB1 promotes inflammation-mediated prostate cancer progression. Mol Cancer Res. 2019:17:845-59.

38. Strating JR, Martens GJ. The p24 family and selective transport processes at the ER-Golgi interface. Biol Cell. 2009;101:495-509.

39. Aber R, Chan W, Mugisha S, Jerome-Majewska LA. Transmembrane emp24 domain proteins in development and disease. Genet Res (Camb). 2019;101:e14.

40. Jerome-Majewska LA, Achkar T, Luo L, Lupu F, Lacy E. The trafficking protein Tmed2/p24beta(1) is required for morphogenesis of the mouse embryo and placenta. Dev Biol. 2010;341:154-66.

41. Jenne N, Frey K, Brugger B, Wieland FT. Oligomeric state and stoichiometry of p24 proteins in the early secretory pathway. J Biol Chem. 2002:277:46504-11.

42. Shi-Peng G, Chun-Lin C, Huan W, Fan-Liang M, Yong-Ning C, Ya-Di Z, Guang-Ping Z, Ye-Ping C. TMED2 promotes epithelial ovarian cancer growth Oncotarget. 2017;8:94151-65.

43. Lin X, Liu J, Hu SF, Hu X. Increased expression of TMED2 is an unfavorable prognostic factor in patients with breast cancer. Cancer Manag Res. 2019;11:2203-14

44. Ha M, Moon H, Choi D, Kang W, Kim JH, Lee KJ, Park D, Kang CD, Oh SO, Han ME, et al. Prognostic role of TMED3 in clear cell renal cell carcinoma: a retrospective multi-cohort analysis. Front Genet. 2019;10:355.

45. Vainio P, Mpindi JP, Kohonen P, Fey V, Mirtti T, Alanen KA, Perälä M, Kallioniemi O, lljin K. High-throughput transcriptomic and RNAi analysis identifies AIM1, ERGIC1, TMED3 and TPX2 as potential drug targets in prostate cancer. PLoS ONE. 2012;7:e39801.

46. Pei J, Zhang J, Yang X, Wu Z, Sun C, Wang Z, Wang B. TMED3 promotes cell proliferation and motility in breast cancer and is negatively modulated by miR-188-3p. Cancer Cell Int. 2019;19:75.

47. Zheng H, Yang Y, Han J, Jiang WH, Chen C, Wang MC, Gao R, Li S, Tian T, Wang J, et al. TMED3 promotes hepatocellular carcinoma progression via IL-11/STAT3 signaling. Sci Rep. 2016;6:37070.

48. Zhang $X$, Luo Y, Li Q. TMED3 promotes proliferation and migration in breast cancer cells by activating Wnt/ $\beta$-catenin signaling. Onco Targets Ther. 2020;13:5819-30

49. Mishra S, Bernal C, Silvano M, Anand S, Ruiz IAA. The protein secretion modulator TMED9 drives CNIH4/TGFalpha/GLI signaling opposing TMED3-WNTTCF to promote colon cancer metastases. Oncogene. 2019;38:5817-37.

\section{Publisher's Note}

Springer Nature remains neutral with regard to jurisdictional claims in published maps and institutional affiliations. 